\title{
Sulfate Conjugation of Various Phenols by Liver-Soluble Fraction of Goldfish
}

\author{
Kunio Kobayashi, ${ }^{*}$ Shigeo Kimura, ${ }^{*}$ and Yuji Oshima* \\ (Accepted September 5, 1983)
}

\begin{abstract}
A study has been made of the capability of the sulfate conjugating enzyme system in the liversoluble fraction from goldfish Carassius auratus, to phenol and twenty-one phenolic compounds as follows at various concentrations from 0.00067 to $33.3 \mathrm{~mm}$ in reaction media: (1) chlorophenols $(o-; p-; 2,4-; 2,4,5-; 2,4,6-; 2,3,4,6-; 2,3,4,5,6-)$, (2) aminophenols $(o-; p-)$, (3) nitrophenols $(m-; o-;$ $p-; 2,4-; 2,4,6-)$, (4) polyphenols (resorcinol; catechol; pyrogallol), (5) other phenols ( $p$-cresol; $o, o^{\prime}$ biphenol; phenolphthalein; phenol red).

The liver-soluble fraction showed fairly high activities of the sulfate conjugation for half of the tested phenols corresponding to $53-116 \%$ of that for phenol $(246 \mathrm{nmol} / \mathrm{h} / \mathrm{g}$-liver $)$, while the negligible conjugation for less than $5 \%$ of that for phenol was observed only in three phenols, i.e., 2,4-dinitrophenol, 2,4,6-trinitrophenol and phenol red. On the other hand, some phenols which showed low sulfate conjugation among the tested phenols such as pentachlorophenol strongly inhibited the sulfate conjugating enzyme system.
\end{abstract}

In our previous papers, it has been demonstrated that goldfish Carassius auratus, is able to form the sulfate conjugates of phenol ${ }^{1)}$ and pentachlorophenol (PCP), ${ }^{2)}$ and excretes the conjugates in surrounding water ${ }^{1,2)}$ and also in the urine. ${ }^{3)}$

In a further study ${ }^{4}$ ) using liver slices from several kinds of fishes, the sulfate conjugation of phenol was confirmed in vitro. The localization of the enzyme system responsible for the sulfate conjugation of phenol in the soluble fraction of fish livers has been also confirmed. ${ }^{\text {s) }}$

The present study was undertaken to elucidate the capability of the sulfate conjugating enzyme to various phenols including $P C$ ? which had not been conjugated with sulfate by liver slices, ${ }^{4}$ ) and also to examine the inhibitory effect of some phenols on the phenol-sulfate conjugation, using the liversoluble fraction from goldfish which showed the highest conjugating activity among the tested fishes in the preceding paper. ${ }^{5)}$

\section{Materials and Methods}

\section{Preparation of Liver-Soluble Fraction}

After two days starvation, goldfish (approx. body weight, $50 \mathrm{~g}$ ) were dissected after blood-letting by decapitation. The hepatopancreas (liver) obtained from the fish was homogenized with 9 volumes of ice-cold $0.25 \mathrm{M}$ sucrose- $10 \mathrm{~mm}$ tris(hydroxymethyl)- aminomethane (Tris)- $\mathrm{HCl}$ buffer solution ( $\mathrm{pH} 7.5)$ by a Potter-Elvehjem type glass-teflon homogenizer in a cold room at $5^{\circ} \mathrm{C}$. The homogenate was fractionated by centrifugation, using an ultracentrifuge (Hitachi 55P-2; rotor RP-65) as shown in the preceding paper. ${ }^{b)}$

\section{Determination of Sulfate Conjugating Activity for Various Phenols}

The sulfate conjugating activity for various phenols in the liver-soluble fraction from goldfish was determined by a procedure shown in Fig. 1, using ${ }^{8}{ }^{8} \mathrm{~S}_{2} \mathrm{~K}_{2} \mathrm{SO}_{4}$. The experiment was performed on phenol and twenty-one phenolic compounds as follows at various concentrations from 0.00067 to $33.3 \mathrm{~mm}$ in reaction media.

1. Chlorophenols: $o$-chlorophenol $(o-\mathrm{CP}) ; p$ chlorophenol ( $p$-CP); 2,4-dichlorophenol (2,4-CP); 2,4,5-trichlorophenol (2,4,5-CP); 2,4,6-trichlorophenol $(2,4,6-\mathrm{CP}) ; 2,3,4,6$-tetrachlorophenol $(2,3,4$, 6-CP); pentachlorophenol (PCP).

2. Aminophenols: o-aminophenol (o-AP); $p$ aminophenol ( $p$-AP).

3. Nitrophenols: $o$-nitrophenol $(o-\mathrm{NP}) ; m$ nitrophenol $(m$-NP); $p$-nitrophenol $(p$-NP); 2,4dinitrophenol (2,4-NP); 2,4,6-trinitrophenol $(2,4,6-$ NP).

4. Polyphenols: resorcinol; catechol; pyrogallol.

* Laboratory of Fishery Environmental Science, Faculty of Agriculture, Kyushu University, Fukuoka 812, Japan (小林邦男 - 木村繁夫-大嶋雄治: 九州大学農学部水産增殖環境学教室). 


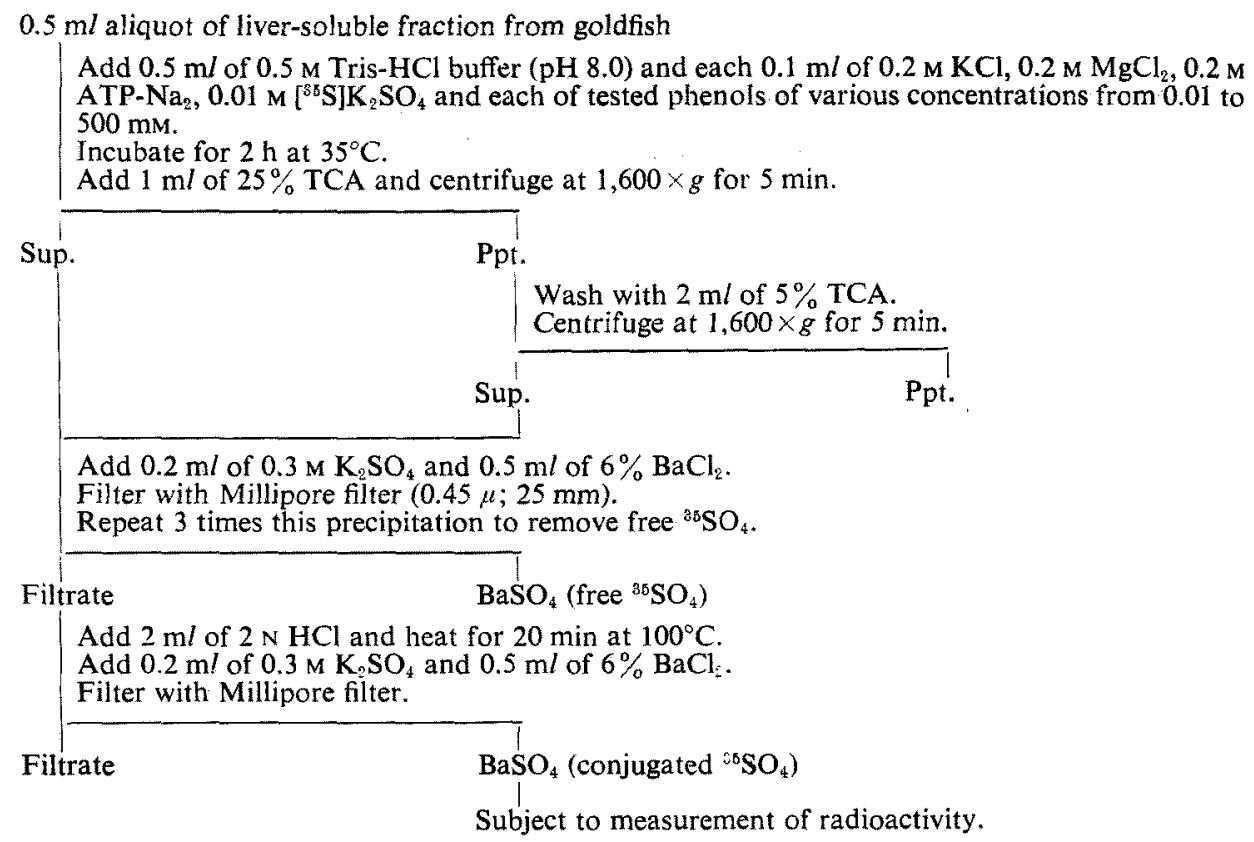

Fig. 1. Determination of sulfate conjugating activity for various phenols in the liver-soluble fraction from goldfish.

5. Other phenols: $p$-cresol; $o, o^{\prime}$-biphenol; phenolphthalein; phenol red.

\section{Measurement of Radioactivity}

The precipitate of $\mathrm{BaSO}_{4}$ containing ${ }^{35} \mathrm{SO}_{4}$ was filtered off on the Millipore filter (pore size, $0.45 \mu$; diam., $25 \mathrm{~mm}$ ) as a uniform thin layer of $18 \mathrm{~mm}$ in diameter. The radioactivity of the precipitate was measured by a G-M counter (Aloka TDC-1) with a mica window $\left(1.5 \mathrm{mg} / \mathrm{cm}^{2}\right)$.

\section{Effect of Some Phenols on Phenol-Sulfate Con- jugation}

PCP, 2,3,4,6-CP, 2,4,6-CP, 2,4,6-NP, 2,4-NP, p-AP, $o, o^{\prime}$-biphenol and pyrogallol which showed relatively low sulfate conjugation among the tested phenols were subjected to a further experiment regarding their inhibitory effect on the sulfate conjugation of phenol by the liver-soluble fraction from goldfish.

The tested phenols were added in the final concentrations of 0.067 and $0.67 \mathrm{~mm}$ to the respective reaction media containing $3.33 \mathrm{~mm}$ of phenol. The sulfate conjugating activities in the media containing phenol and each of the tested phenols were determined according to the procedure shown in Fig. 1.

\section{Results and Discussion}

Sulfate Conjugating Activity for Various Phenols

1. Chlorophenols: Fig. 2 shows the relation between the amounts of sulfate conjugated with the tested chlorophenols and their concentrations in reaction media. $p$-CP showed a similar pattern of the conjugate formation to that in phenol. Other tested chlorophenols except 2,3,4,6-CP and PCP also showed respective maximum values comparable to that in phenol, but their sulfate conjugation occurred restrictedly in lower concentration regions according as their $\mathrm{Cl}$-atom number increased. The maximum conjugation of $2,3,4,6-$ $\mathrm{CP}$ and PCP was observed at 0.067 and $0.05 \mathrm{~mm}$ corresponding to ca. $1 / 4$ and $1 / 15$ of that of phenol, respectively.

When goldfish were transferred from PCPwater to PCP-free water, the PCP absorbed by the fish was quickly excreted into surrounding water with a half-life ca. $10 \mathrm{~h}^{(\mathrm{)})}$ mostly as its sulfate conjugate accompanied with a small amount of freeform. ${ }^{2)}$ The formation of PCP-sulfate conjugate in vivo was confirmed in vitro using the liver-soluble fraction from goldfish as shown in Fig. 2, although it had not been detected in our previous study by fish liver slices. ${ }^{4)}$

2. Aminophenols: As shown in Fig. 3, the maximum conjugation of $o-\mathrm{AP}$ and $p$-AP was 


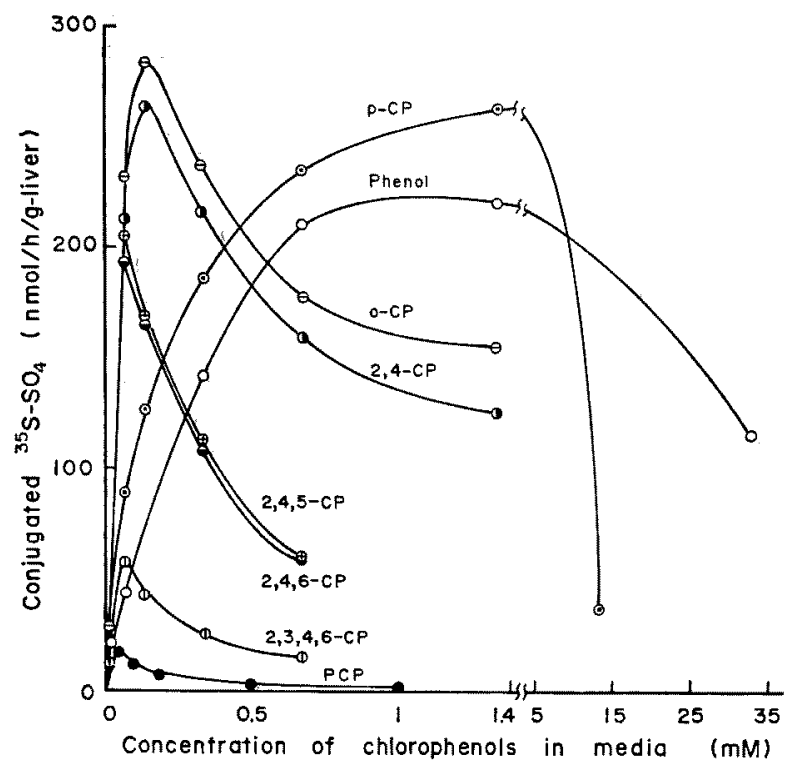

Fig. 2. Sulfate conjugation of chlorophenols by the liver-soluble fraction from goldfish.

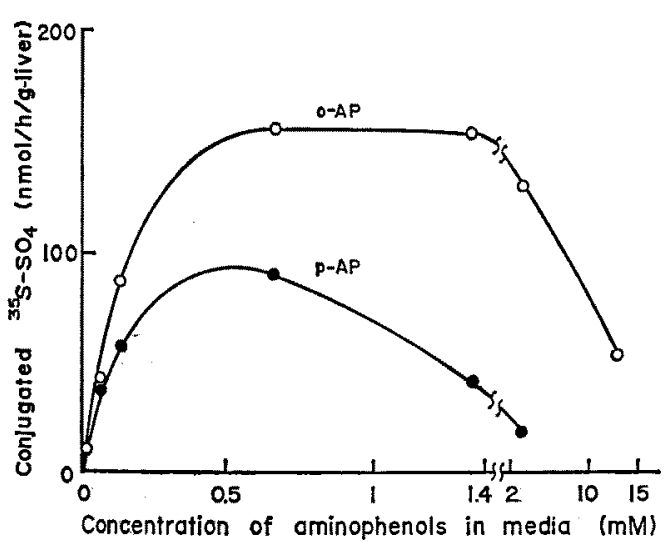

Fig. 3. Sulfate conjugation of aminophenols by the liver-soluble fraction from goldfish.

observed at $0.67-1.33 \mathrm{~mm}$ and ca. $0.67 \mathrm{~mm}$ corresponding to $63 \%$ and $37 \%$ of that of phenol, respectively.

3. Nitrophenols: Fig. 4 shows the relation between the amounts of sulfate conjugated with the tested nitrophenols and their concentrations in media. The patterns of the conjugate formation in $m$-NP and $o$-NP were similar to that in phenol. The formation of the conjugate in $p$-NP increased with the increase of its concentration in media from 0.0067 to $3.33 \mathrm{~mm}$ and the maximum value was about half of that in $m$-NP. However, the sulfate conjugation of 2,4-NP and 2,4,6-NP was almost negligible at their concentrations from 0.0067 to $1.33 \mathrm{~mm}$.

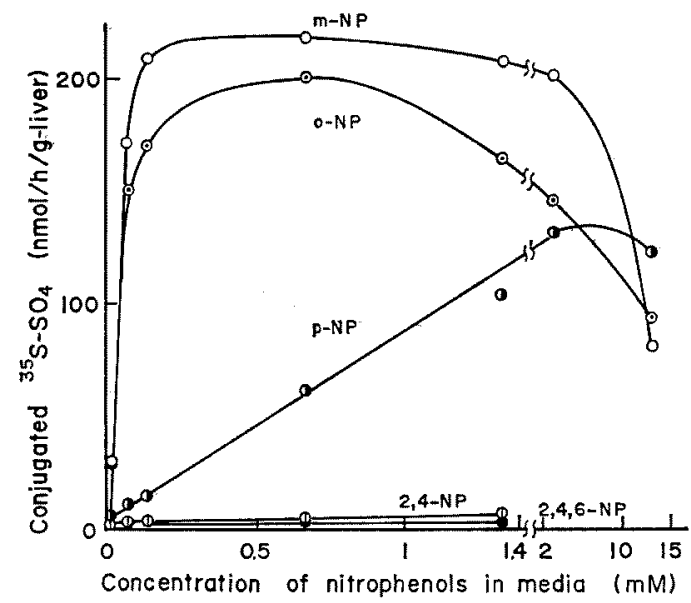

Fig. 4. Sulfate conjugation of nitrophenols by the liver-soluble fraction from goldfish.

4. Polyphenols: The formation of sulfate conjugates in resorcinol, catechol and pyrogallol are shown in Fig. 5. The formation patterns in resorcinol and catechol were similar to that in phenol, whereas the pyrogallol-sulfate conjugation reached a maximum at $0.133 \mathrm{~mm}$ and subsequently decreased with the increase of its concentration in media. This result suggests that the increase of hydroxyl group in polyphenols restricts the formation of their sulfate conjugates within their lower concentration regions in media as well as the increase of $\mathrm{Cl}$-atom number in chlorophenols as shown in Fig. 2. 


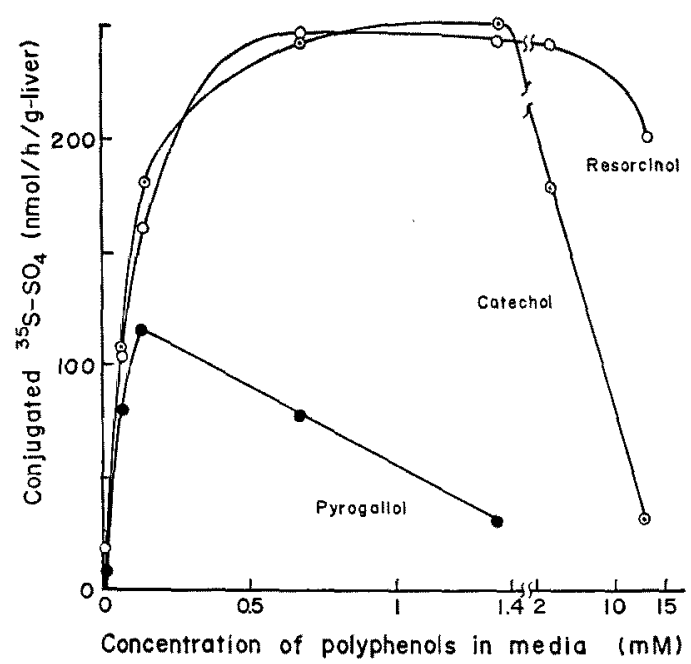

Table 1. Sulfate conjugating activities for various phenols in the liver-soluble fraction from goldfish

\begin{tabular}{lc}
\hline \multicolumn{1}{c}{ Tested phenols } & $\begin{array}{c}\text { Maximum enzyme } \\
\text { activity } \\
\text { (nmol/h/g-liver) }\end{array}$ \\
\hline o-Chlorophenol & 285 \\
p-Chlorophenol & 265 \\
2,4-Dichlorophenol & 265 \\
2,4,5-Trichlorophenol & 205 \\
2,4,6-Trichlorophenol & 192 \\
2,3,4,6-Tetrachlorophenol & 64 \\
Pentachlorophenol & 17 \\
\hline$o-$ Aminophenol & 156 \\
$p$-Aminophenol & 91 \\
\hline$m$-Nitrophenol & 221 \\
$o-$ Nitrophenol & 200 \\
$p$-Nitrophenol & 130 \\
2,4-Dinitrophenol & 6 \\
2,4,6-Trinitrophenol & 3 \\
\hline Resorcinol & 247 \\
Catechol & 254 \\
Pyrogallol & 114 \\
\hline$p$-Cresol & 171 \\
$o, o^{\prime}-$ Biphenol & 49 \\
Phenolphthalein & 32 \\
Phenol red & 5 \\
\hline Phenol & 246 \\
\hline
\end{tabular}

Fig. 5. Sulfate conjugation of polyphenols by the liver-soluble fraction from goldfish.

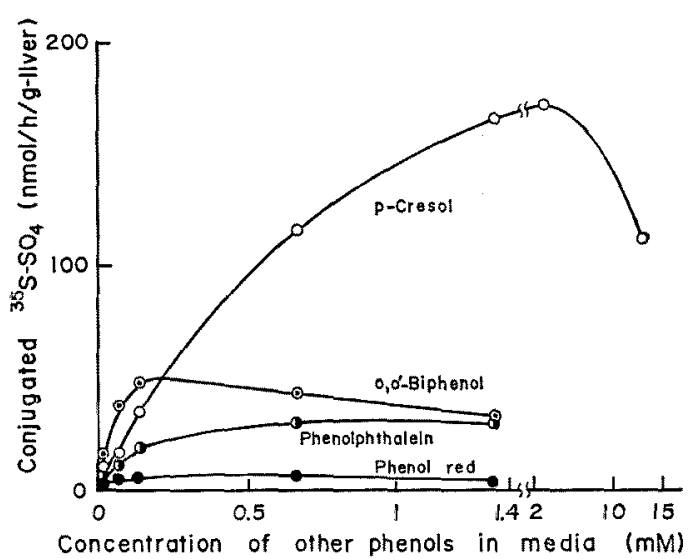

Fig. 6. Sulfate conjugation of other phenols by the liver-soluble fraction from goldfish.

5. Other phenols: Fig. 6 shows the formation of sulfate conjugates in $p$-cresol, $o, o^{\prime}$-biphenol, phenolphthalein and phenol red. The conjugate formation in $p$-cresol was relatively high, while that in the others especially in phenol red was very low.

The sulfate conjugating activity in the liversoluble fraction from goldfish varied widely according to the concentrations of phenols in media as shown in Figs. 2-6. The maximum values in the tested phenols are summed up in Table 1 at their optimum concentrations. The liver-soluble fraction from goldfish showed fairly high activities of the sulfate conjugation for most of the tested phenols. This indicates that the sulfate conjugation plays an important role as a general detoxication mechanism for phenolic compounds in fish.

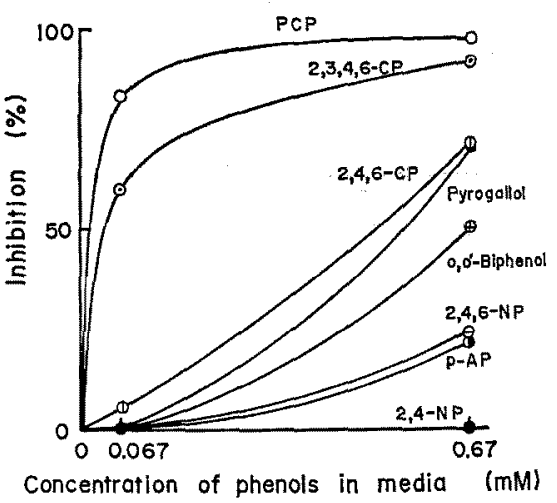

Fig. 7. Inhibitory effect of some phenols on the sulfate conjugation of phenol by the liver-soluble fraction from goldfish.

Each reaction medium contained $3.33 \mathrm{~mm}$ of phenol.

Effect of Some Phenols on Phenol-Sulfate Conjugation

The inhibitory effect of PCP, $2,3,4,6-\mathrm{CP}, 2,4,6$ CP, 2,4,6-NP, 2,4-NP, p-AP, o, o'-biphenol and pyrogallol on the phenol-sulfate conjugation by the 
liver-soluble fraction from goldfish was shown in Fig. 7.

PCP inhibited by $83 \%$ and almost $100 \%$ the phenol-sulfate conjugation at 0.067 and $0.67 \mathrm{~mm}$, respectively. 2,3,4,6-CP showed a similar inhibition to that in PCP. The other tested phenols except 2,4-NP also inhibited the conjugation by $20-70 \%$ at $0.67 \mathrm{~mm}$, though their inhibition was negligibly small at $0.067 \mathrm{~mm}$.

This result indicates that the low sulfate conjugation of 2,4-NP as shown in Fig. 4 must be due to its low reactivity in the conjugation, because it does not inhibit the sulfate conjugation of phenol, whereas the low sulfate conjugation mostly restricted in the lower concentration regions in other tested phenols as shown in Figs. 2-6, is mainly due to their inhibitory effect on the enzyme system concerning sulfate conjugation.

As demonstrated in our previous paper, ${ }^{6)}$ goldfish placed in PCP-water excretes the absorbed PCP into the water while absorbing it from the water, resulting in the accumulation of PCP in the fish which is equal to the difference between absorption and excretion. Although the excretion of PCP from the fish is promoted by the sulfate conjuga- tion, ${ }^{2,3)}$ it seems that the increase of PCP concentration in the fish gradually inhibits the conjugation and consequently promotes the PCP accumulation in the fish until it reaches a concentration of about $100 \mu \mathrm{g}-\mathrm{PCP} / \mathrm{g}$-body weight at which time mortality occurs. ${ }^{8)}$

This work was supported in part by a Grant-in Aid for Scientific Research (448059) from the Ministry of Education.

\section{References}

1) K. Kobayashi, H. Akitake, C. Matsuda, and S. Kimura: Bull. Japan. Soc. Sci. Fish., 41, 12771282 (1975).

2) H. Akitake and K. Kobayashi: Bull. Japan. Soc. Sci. Fish., 41, 321-327 (1975).

3) K. Kobayashi and N. Nakamura: Bull. Japan. Soc. Dci. Fish, 45, 1001-1003 (1979).

4) K. Kobayashi, S. Kimura, and H. Akitake: Bull. Japan. Soc. Sci. Fish., 42, 171-177 (1976).

5) S. Kimura, Y. Oshima, and K. Kobayashi: Bull. Japan. Soc. Sci. Fish., 48, 433-437 (1982).

6) K. Kobayashi and H. Akitake: Bull. Japan. Soc. Sci. Fish., 41, 87-93 (1975). 